\title{
Influência da Estrutura na Curva Característica de Retenção e no Comportamento Colapsível de um Solo Tropical
}

\author{
Influence of the Structure on the Water Retention Characteristic Curve and the Collapsible Behavior of a \\ Tropical Soil
}

\section{Natália Medeiros de Oliveira ${ }^{1}{ }^{\circledR}$, Sérgio Leandro Scher Dias Neto ${ }^{\circledR}{ }^{\circledR}$, Roberto Lopes

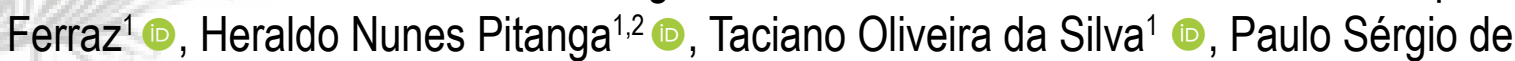 Almeida Barbosa ${ }^{1}$ (1) \& Dario Cardoso de Lima ${ }^{1}$ (1)}

\author{
${ }^{1}$ Universidade Federal de Viçosa, Departamento de Engenharia Civil, Viçosa, MG, Brasil \\ 2Universidade Federal de Juiz de Fora, Departamento de Transportes e Geotecnia, Juiz de Fora, MG, Brasil \\ E-mail: eng.natalia@hotmail.com; sergio.scher.7@gmail.com; rlferraz@ufv.br; heraldo.pitanga@ufv.br; taciano.silva@ufv.br; \\ pbarbosa@ufv.br; declima@ufv.br
}

\section{Resumo}

Esta pesquisa trata da avaliação da influência das estruturas provenientes de amostras de mesmas densidades secas, reconstituídas por dois processos de compressão (hidrostática, sob umidade de moldagem de 29,5\%, e edométrica, sob umidade de moldagem de $57,6 \%$ ), na curva característica e no comportamento colapsível de um solo argiloso tropical compactado. A avaliação baseou-se em resultados de ensaios edométricos (com e sem medida de colapso) e nas propriedades das curvas características, as quais sugeriram a formação de agregações das partículas para os dois teores de umidade de reconstituição analisados, sendo que, para baixos valores de sucção, a macroestrutura governa a dessaturação inicial das amostras. Presume-se que, para a amostra reconstituída no teor de umidade mais baixo (Amostra 1), os fenômenos de capilaridade são mais importantes na determinação do seu comportamento hidromecânico, enquanto para a amostra reconstituída na umidade mais alta (Amostra 2), destacam-se também os fenômenos derivados de forças de adsorção. As curvas de compressibilidade (e x $\log \sigma_{v}$ ) apontaram que a redução da sucção foi responsável pelo colapso da estrutura dos corpos de prova da Amostra 1, sendo que o nível de tensão em que foi induzido o colapso teve pouca influência na condição final, quando comparado ao efeito da estrutura. Os critérios adotados para a avaliação do potencial de colapso (PC) evidenciaram elevada susceptibilidade ao colapso do solo na condição da Amostra 1, para uma extensa faixa de tensões verticais.

Palavras-chave: Solos tropicais; Curva característica; Ensaios edométricos

\begin{abstract}
This study evaluated the influence of structures from samples of the same dry density, reconstituted by two compression processes (hydrostatic, under moisture content of $29.5 \%$, and oedometric, under moisture content of $57.6 \%$ ), on the characteristic curve and on the collapsible behavior of a compacted tropical clayey soil. The evaluation was based on results of oedometer tests (with and without measure of collapse) and on properties of the characteristic curves, which suggested the formation of particle aggregations for the two reconstitution moisture contents analyzed, and for low suction values, the macrostructure governs the initial desaturation of the samples. It is presumed that, for the sample reconstituted at the lowest moisture content (Sample 1), the capillary phenomena are more important in determining its hydromechanical behavior, whereas for the sample reconstituted at higher moisture (Sample 2) also stand out the phenomena derived from adsorption forces. The compressibility curves $\left(\mathrm{e} x \log \sigma_{v}\right)$ indicated that the reduction of suction was responsible for the collapse of the specimen structure of Sample 1, and the stress level at which the collapse was induced had little influence on the final condition when compared to the structure effect. The criteria adopted for the evaluation of the collapse potential (PC) showed a high susceptibility to soil collapse in the condition of Sample 1, for an extensive range of vertical stresses.
\end{abstract}

Keywords: Tropical soils; Characteristic curve; Oedometric tests 


\section{Introdução}

Solos argilosos são utilizados em diversas aplicações geotécnicas e geoambientais. Quando compactados, tais solos são encontrados em barragens de terra, em camadas de pavimentos rodoviários e em aterros sanitários, nestes últimos como barreiras impermeáveis na base e na camada de cobertura.

Embora solos compactados apresentem elevada resistência e baixa compressibilidade, estão sujeitos a grandes variações volumétricas e a alterações em seus estados de tensões decorrentes das variações ambientais (Tatsuoka \& Correia, 2018). Como consequência, apesar de a estrutura obtida durante a compactação ser um indicativo do comportamento dos solos frente às solicitações, a interação contínua com o meio ambiente produz deformações irreversíveis, que alteram a resposta hidromecânica do solo no campo, no que diz respeito às condições de compactação (Della Vecchia et al., 2015).

O comportamento volumétrico de solos argilosos compactados, contudo, é bastante complexo devido à presença da fase de ar durante o processo de compactação, que caracteriza o estado não saturado, e às várias estruturas resultantes de diferentes métodos de compactação (Ajdari et al., 2013; Cui et al., 2013; Han \& Vanapalli, 2016a; Kodikara et al., 2016; Islam \& Kodikara, 2016).

Portanto, uma ferramenta fundamental para a descrição do comportamento hidromecânico dos solos não saturados é a curva característica de retenção de água, que, além de permitir a obtenção da sucção no solo em função da quantidade de água existente, também fornece informações importantes sobre a estrutura do solo e desempenha um papel essencial na formulação de equações constitutivas aplicáveis aos solos não saturados (Maranha das Neves, 2016).

Segundo Vanapalli et al. (1999), assim como nos solos argilosos naturais, os solos argilosos compactados apresentam, tipicamente, dois níveis estruturais: a microestrutura, representada pela associação das partículas individuais do solo e seus vazios internos (microvazios), e a macroestrutura, constituída pelo arranjo das agregações de partículas de argila (grumos de argilominerais) e os macrovazios resultantes. Baseados em observações de imagens de microscópios eletrônicos de varredura e de ensaios de porosimetria por intrusão de mercúrio, diversos autores relataram que a organização desses níveis estruturais, isto é, da estrutura do solo, é substancialmente influenciada pelo teor de umidade de compactação (Sivakumar \& Wheeler, 2000; Romero et al., 2011; Zhang et al., 2018). Esses autores ainda afirmam que a estrutura de solos compactados no ramo seco da curva de compactação, na energia do ensaio Proctor Normal, é caracterizada pela formação de agregações de partículas de argila (estrutura floculada), ao passo que, no ramo úmido da curva de compactação, prevalece uma distribuição relativamente uniforme de partículas (estrutura dispersa).

Como resultado, segundo Alonso et al. (2013), em estruturas floculadas, verifica-se que a macroestrutura, caracterizada por macroporos abertos e microvazios oclusos, governa a relação entre o teor de umidade e a rigidez de solos argilosos compactados. Segundo esses autores, a água localizada nos macroporos é identificada como de natureza capilar, portanto, diferente da água que preenche os vazios dos agregados argilosos (microvazios). Por isso, Li et al. (2016) afirmam que corpos de prova compactados em diferentes teores de umidade, provenientes de um mesmo solo, apesar de apresentarem mesma textura, mineralogia e densidade seca, apresentam diferentes potenciais de retenção de água e, consequentemente, diferentes potenciais de colapso, resultando em materiais fundamentalmente diferentes.

Vilar \& Rodrigues (2011) e Benatti et al. (2013), ao avaliarem o potencial de colapso de solos residuais brasileiros, afirmam que a estrutura tem uma influência determinante no comportamento que os solos colapsíveis exibem. Segundo esses autores, os solos colapsíveis apresentam uma estrutura metaestável, com rigidez temporária mantida por forças capilares, forças de adsorção ou pela presença de algum agente cimentante. Esses autores ainda afirmam que a sucção capilar é o principal fator que contribui para a resistência temporária dos solos colapsíveis não saturados e que, independente das ligações que mantêm essas estruturas, os solos susceptíveis ao colapso apresentam grande sensibilidade à ação da água.

Apesar de numerosos estudos recentes a respeito das propriedades hidromecânicas de solos não saturados ao redor do globo (Ng et al., 2016; Han \& Vanapalli, 2016b; Bakir et al., 2017; Zou et al., 2018; Habasimbi \& Nishimura, 2019), investigações dessas propriedades, referentes a solos tropicais não saturados, em especial para corpos de prova compactados, carecem de estudos adicionais aos constatados na literatura (Crispim et al., 2011; Benatti et al., 2013; Otalvaro et al., 2015, 2016; Cordão Neto et al., 2018). Além disso, o desenvolvimento de um método para a avaliação da influência da sucção no comportamento hidromecânico dos solos não saturados, a partir de ensaios geotécnicos corriqueiros, traria uma contribuição significativa para a comunidade técnica, uma vez que os conceitos da mecânica dos solos não saturados poderiam ser utilizados na prática da engenharia geotécnica (Mascarenha et al., 2016; Li et al., 2016).

Em relação a esse contexto, essa pesquisa visa investigar a influência da estrutura na curva característica de retenção de água e no comportamento colapsível de um solo argiloso tropical compactado. Busca-se avaliar a resposta hidromecânica do solo analisado sob os efeitos da 
sucção e do teor de umidade inicial de moldagem, fazendose uso de ensaios simples realizados em laboratórios de mecânica dos solos.

\section{Materiais}

Esta pesquisa foi realizada com um solo residual maduro de gnaisse, de ocorrência expressiva no território brasileiro e, em especial, na Zona da Mata Norte, estado de Minas Gerais (MG), Brasil. Em termos pedológicos, ele é classificado como Latossolo Vermelho-Amarelo, com horizonte B latossólico de tonalidade avermelhada, aspecto poroso e granulometria argilo-areno-siltosa (Resende et al., 2007).

As amostras deformadas do solo foram coletadas no horizonte B de um talude de corte em um local denominado de Alto dos Barbados, dentro do campus da Universidade Federal de Viçosa (UFV), no município de Viçosa - MG, com coordenadas geográficas de Latitude $\left(20^{\circ} 45^{\prime} 11,1\right.$ 'S) e Longitude ( $\left.42^{\circ} 51^{\prime} 31,2^{\prime \prime} \mathrm{W}\right)$. Um mapa referente ao local de coleta das amostras é representado na Figura 1. Após a coleta, as amostras foram adequadamente identificadas e acondicionadas para a realização dos procedimentos experimentais.

\section{Métodos}

A parte experimental da pesquisa consistiu na realização de ensaios de caracterização geotécnica do solo, ensaio de compactação, determinação de curvas características de retenção de água e ensaios edométricos incrementais, com e sem medida de colapso.
A caracterização geotécnica do solo e o ensaio de compactação foram realizados com base em ensaios regulamentados pela Associação Brasileira de Normas Técnicas (ABNT), que consistiram em: análise granulométrica conjunta (ABNT, 2016a); limite de liquidez (ABNT, 2016b); limite de plasticidade (ABNT, 2016c); massa específica real dos grãos (ABNT, 2016d); ensaio de compactação (ABNT, 2016e) e ensaios edométricos incrementais (ABNT, 1990). A determinação das curvas características de retenção de água no solo foi realizada com as técnicas da mesa de tensão e da câmara de pressão (câmara de Richards), conforme procedimentos descritos por Teixeira \& Bhering (2017).

Para analisar a influência da estrutura na curva característica e no comportamento colapsível do solo, foram utilizadas duas amostras reconstituídas com mesmos valores de peso específico seco $\left(\gamma_{\mathrm{d}}\right)$ e índice de vazios $(\mathrm{e})$, porém utilizando diferentes teores de umidade iniciais ou de moldagem e distintos processos de compressão. Assim, para uma das amostras (Amostra 1), foi utilizado o processo de reconstituição por compressão hidrostática, enquanto que para a outra (Amostra 2), foi utilizado o processo de reconstituição por compressão edométrica. Os teores de umidade e processos de reconstituição adotados visaram obter amostras de solo em condições de mesmo índice de vazios, porém distintos graus de saturação e estruturas diferenciadas.

Para obter a Amostra 1, foi adotado um teor de umidade próximo de $2 \%$ abaixo do teor ótimo do ensaio de compactação do solo, na energia do Proctor Normal ( $\mathrm{w}_{\mathrm{ot}}$ $2 \%$ ), sendo que o valor do peso específico seco alcançado
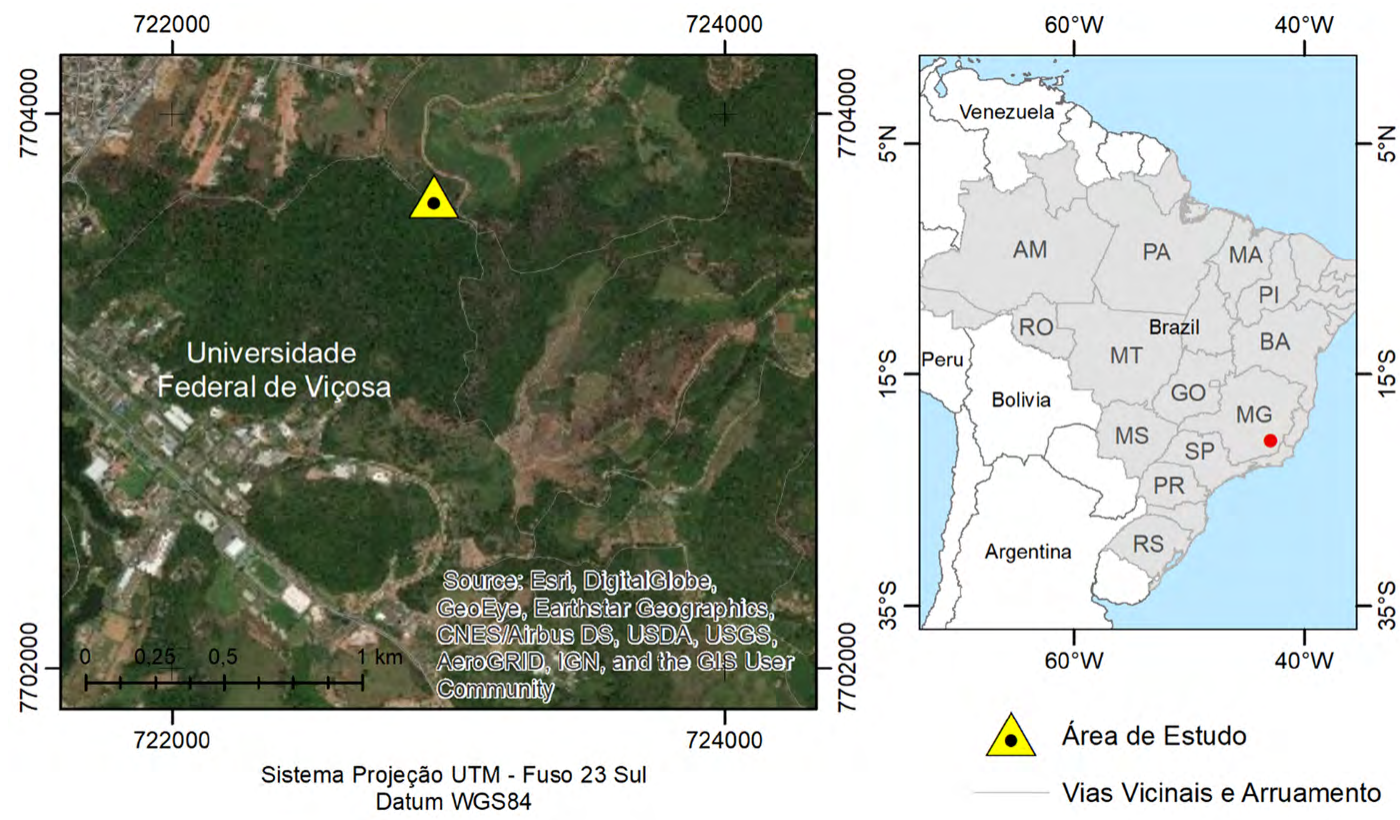

Figura 1 Mapa de localização da coleta das amostras de solo. 
foi dependente do processo de reconstituição utilizado, que, no caso dessa amostra, foi o de compressão hidrostática. Nesse processo, inicialmente, era preparada uma porção de solo com o teor de umidade desejado $\left(\mathrm{w}_{\text {ot }}-2 \%\right)$, a qual era colocada em um molde cilíndrico de PVC, $\operatorname{com} 8,0 \mathrm{~cm}$ de diâmetro e $18,5 \mathrm{~cm}$ de altura, com uma membrana de látex no seu interior, conforme ilustrado na Figura $2 \mathrm{~A}$.

A massa de solo úmido utilizada nas reconstituições por esse processo foi de $720 \mathrm{~g}$, que se refere à quantidade de solo necessária para preencher o molde cilíndrico, sem induzir a compactação inicial na amostra. $\mathrm{Na}$ base e no topo do molde, foram colocados, respectivamente, um disco perfurado e um top cap, que permitiram a selagem das extremidades da membrana de borracha com o-rings e o seu manuseio para colocação sobre um berço de PVC (Figura 2B). Em seguida, o conjunto foi colocado dentro de uma câmara de compressão hidrostática (Figura 2C), conectando-se a extremidade do top cap ao topo da câmara, de forma a permitir a saída do ar durante o período de compressão. Após o preenchimento da câmara com água, foi aplicada uma pressão de confinamento de $100 \mathrm{kPa}$, por sete dias, período este testado e considerado ideal para a completa compressão da amostra. A adoção do valor de $100 \mathrm{kPa}$ teve como objetivo obter uma amostra com elevado índice de vazios, o que, segundo Benatti et al. (2013), é uma das características para configurar um solo colapsível, além de um baixo teor de umidade.

Após a obtenção das amostras reconstituídas hidrostaticamente, foram moldados os corpos de prova para os ensaios edométricos e para a determinação da curva característica de retenção de água, tomando-se o cuidado de utilizar a parte central da amostra (Figura 3A), de modo a eliminar os efeitos de borda. Os corpos de prova foram moldados em anéis metálicos de $54 \mathrm{~mm}$ de diâmetro e 20 mm de altura, conforme ilustrado nas Figuras $3 \mathrm{~B}$ e $3 \mathrm{C}$. A partir dos valores do teor de umidade de moldagem (w) e do peso específico úmido $(\gamma)$, foi calculado o valor do peso específico seco $\left(\gamma_{\mathrm{d}}\right)$ alcançado com o processo de reconstituição hidrostática, o qual serviu de referência para a definição dos parâmetros para a reconstituição da Amostra 2.

Visando estudar o comportamento do material com um mesmo índice de vazios, porém reconstituído na condição saturada, a obtenção da Amostra 2 foi realizada mantendo-se o mesmo peso específico seco da Amostra 1 (mesmo índice de vazios) e um valor de teor de umidade que resultasse em um ponto situado sobre a curva de saturação do solo (Figura 4).

De forma a garantir a saturação completa dos corpos de prova da Amostra 2, adotou-se o processo de reconstituição edométrica, partindo-se de uma porção de solo com teor de umidade próximo ao limite de liquidez (LL), que foi comprimida em um anel metálico até atingir o mesmo peso específico aparente seco da Amostra 1. Para que, ao final do processo de compressão, fossem obtidos corpos de prova com as dimensões exigidas para os ensaios a serem realizados, foi desenvolvido o dispositivo ilustrado na Figura 5, na base do qual era acoplado um anel metálico de $54 \mathrm{~mm}$ de diâmetro e $20 \mathrm{~mm}$ de altura (Figura 5A). A compressão do solo foi realizada com a tampa do dispositivo, na parte central da qual havia um orifício para possibilitar a saída da água expulsa do solo. Para atingir o mesmo valor de $\gamma_{d}$ da Amostra 1, foi feito o controle da massa de solo seco utilizada em cada reconstituição.

Em função das características das amostras estudadas, os ensaios de compressão edométrica foram realizados de forma diferenciada, sendo que, para a Amostra 1, foram ensaiados quatro corpos de prova, onde o primeiro foi sem inundação (CP1) e os demais (CP2, CP3, CP4) com inundação nas tensões de $12 \mathrm{kPa}$ (início do ensaio), $100 \mathrm{kPa}$ e $1600 \mathrm{kPa}$, respectivamente. Para a Amostra 2, que já se encontrava na condição saturada, foi ensaiado somente um corpo de prova (CP5), utilizando-se os mesmos estágios de tensões dos ensaios com a Amostra 1.

As deformações por colapso foram representadas pelo potencial de colapso (PC) em cada nível de tensão vertical, conforme a Equação 1, proposta por Jennings \& Knight (1975).

$$
P C=\frac{\Delta e}{1+e_{0}}=\frac{\Delta H}{H_{0}} \cdot 100 \%
$$

Em que: $\Delta e$ - variação do índice de vazios devido ao colapso; $e_{0}$-índice de vazios inicial do $\mathrm{CP} 1 ; \Delta H$ - variação da altura do corpo de prova devido ao colapso; $H_{0}$ - altura inicial do corpo de prova CP1.

Jennings \& Knight (1975), com base no valor do potencial de colapso (PC) correspondente à tensão de 200 $\mathrm{kPa}$, apresentaram uma classificação para a susceptibilidade ao colapso dos solos, que leva em consideração a gravidade dos danos em uma obra de engenharia. Uma proposta semelhante foi apresentada por Lutenegger \& Saber (1988), porém para a tensão de referência de $300 \mathrm{kPa}$. Já para Vargas (1978), um solo é considerado colapsível quando PC > $2 \%$, independentemente do nível de tensão. Os critérios de classificação segundo Jennings \& Knight (1975) e Lutenegger \& Saber (1988) encontram-se resumidos no Quadro 1. 


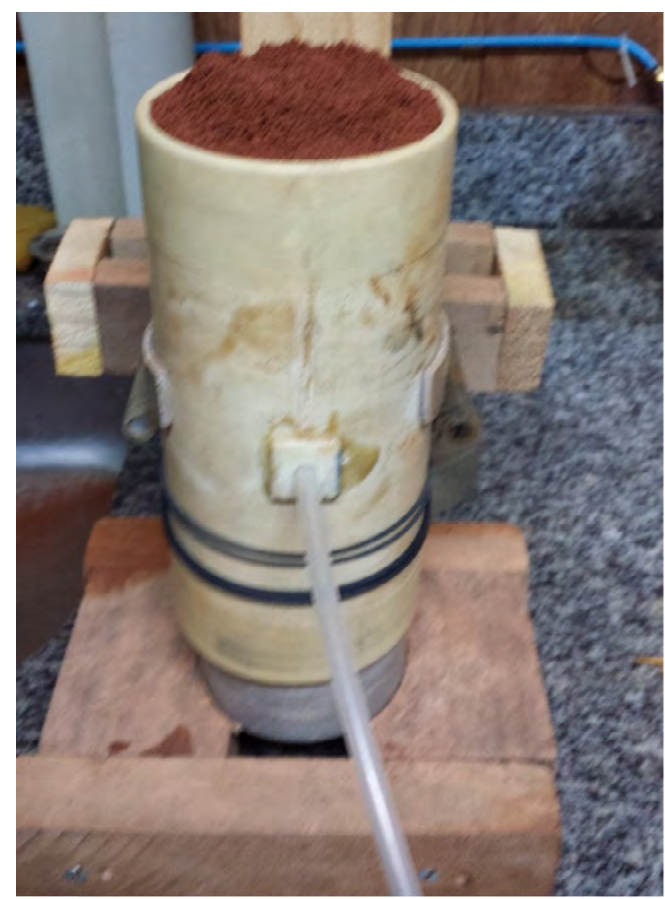

A

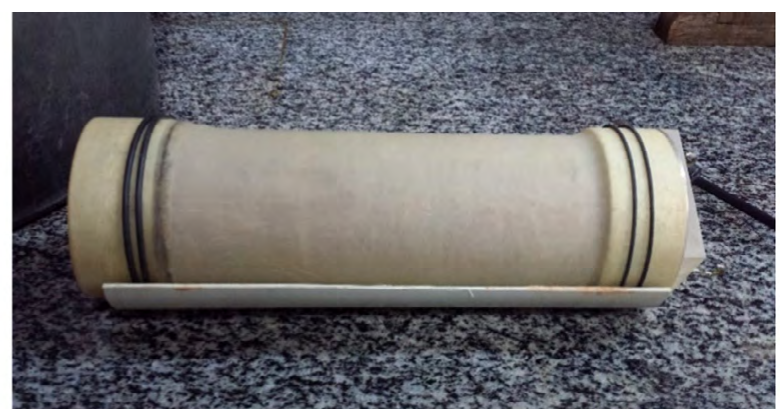

B

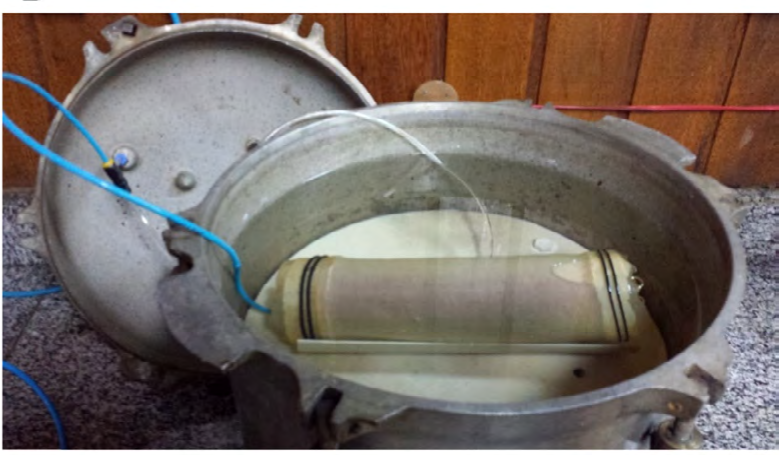

$\mathrm{C}$

Figura 2 Preparação da Amostra 1 para reconstituição hidrostática. A. Deposição da amostra de solo no molde de PVC; B. Amostra vedada para reconstituição; C. Câmara de compressão hidrostática

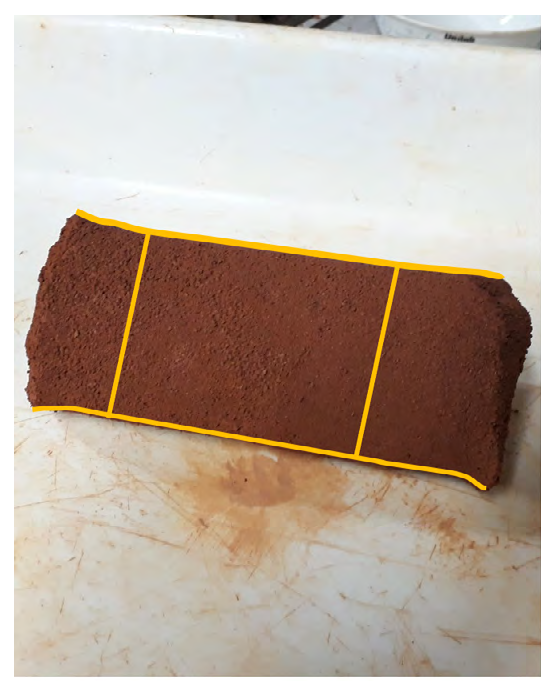

A

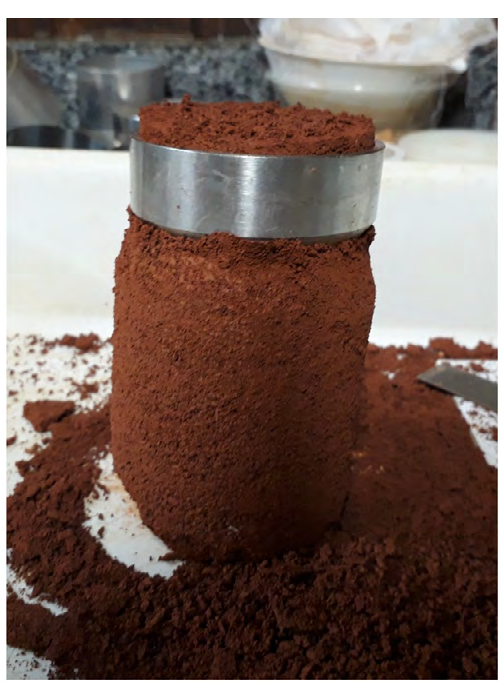

$\mathrm{B}$

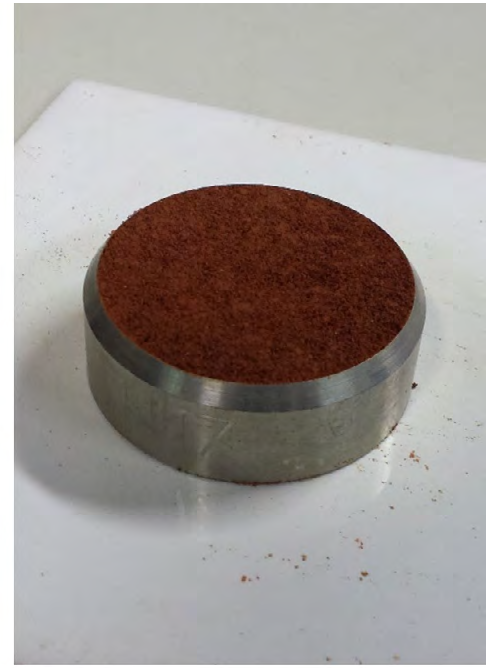

C

Figura 3 Moldagem dos corpos de prova da Amostra 1 para os ensaios edométricos. A. Eliminação dos efeitos de borda; B. Talhagem da amostra; C. Corpo de prova moldado para os procedimentos experimentais.

A redução da sucção em campo nem sempre se dá de forma brusca, como foi imposto pela inundação dos corpos de prova. Para a reprodução do colapso provocado pela redução gradativa e conhecida da sucção, ensaios de compressão edométrica com controle de sucção são recomendados.
É importante mencionar que, além dos critérios para a identificação de solos colapsíveis que empregam ensaios edométricos, existem outros critérios, de caráter regional, desenvolvidos para determinadas ocorrências de solos ou regiões, a partir de conceitos empíricos ou de determinados testes rápidos. Esses critérios, geralmente, baseiam-se nos 


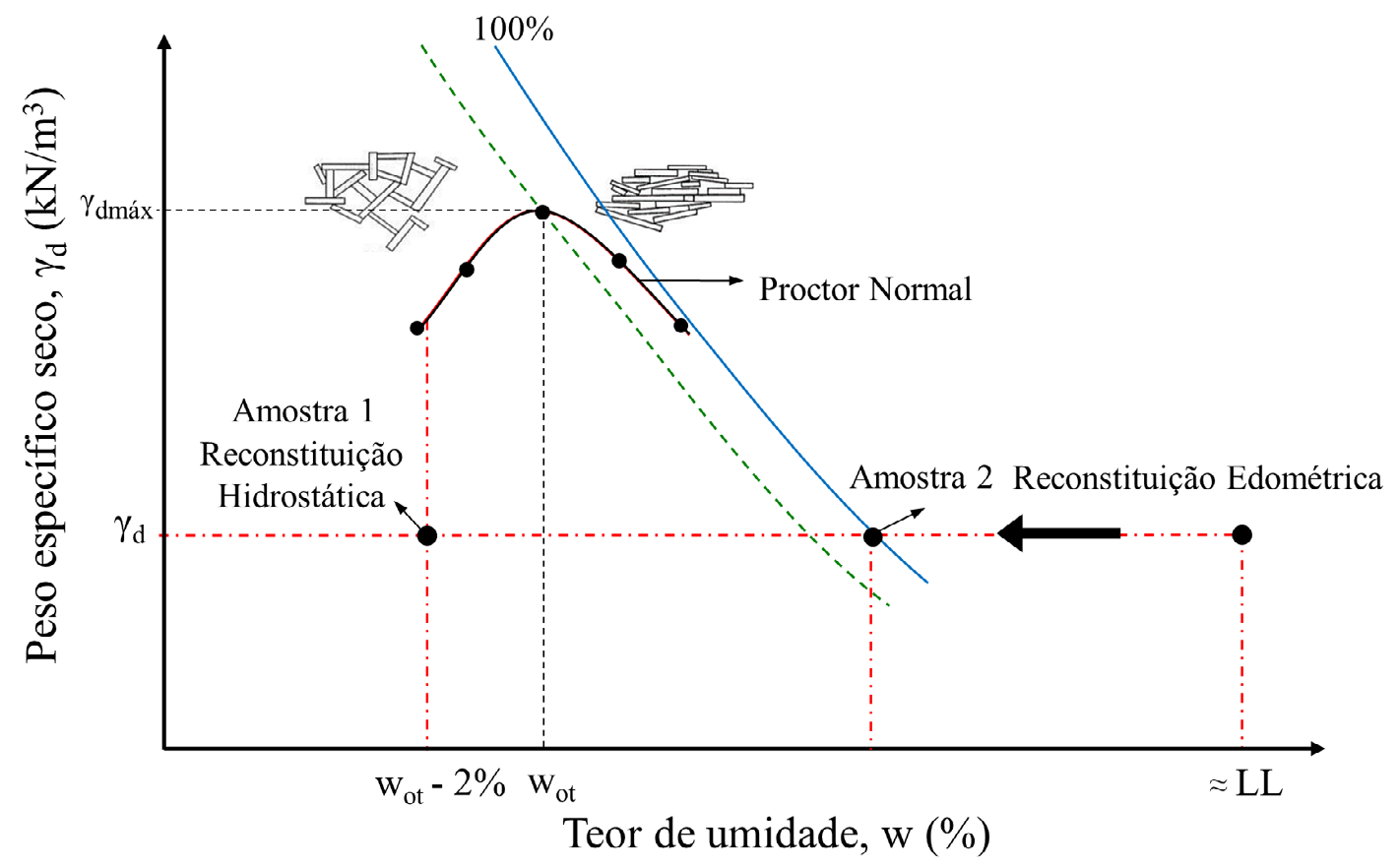

Figura 4 Representação dos procedimentos para reconstituição das Amostras 1 e 2.

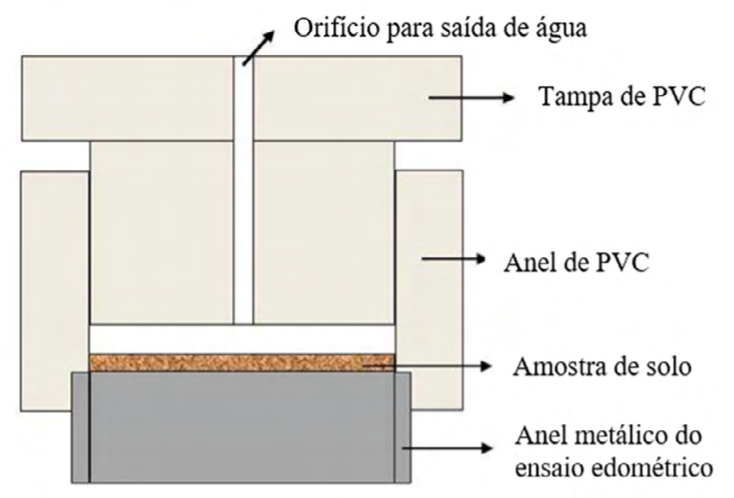

A

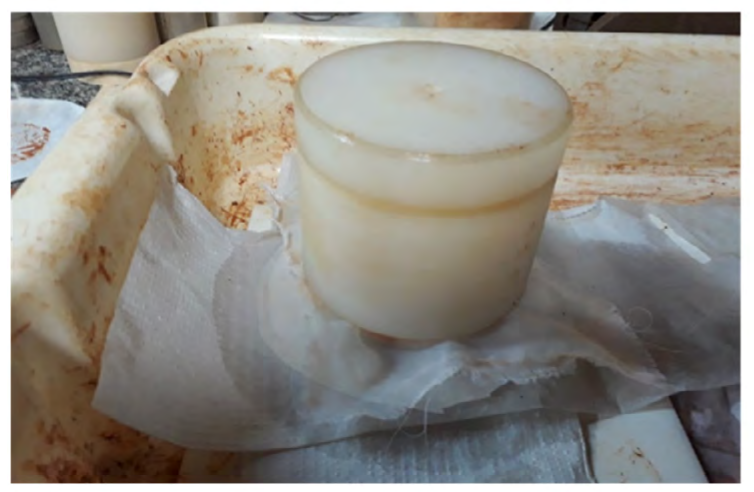

$\mathrm{C}$

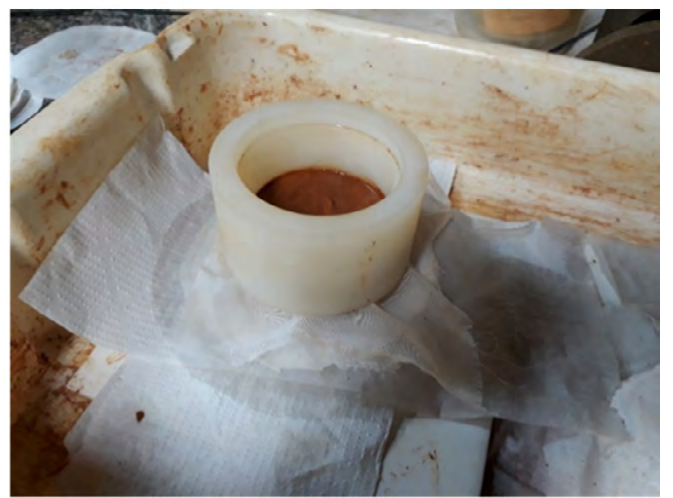

$\mathrm{B}$

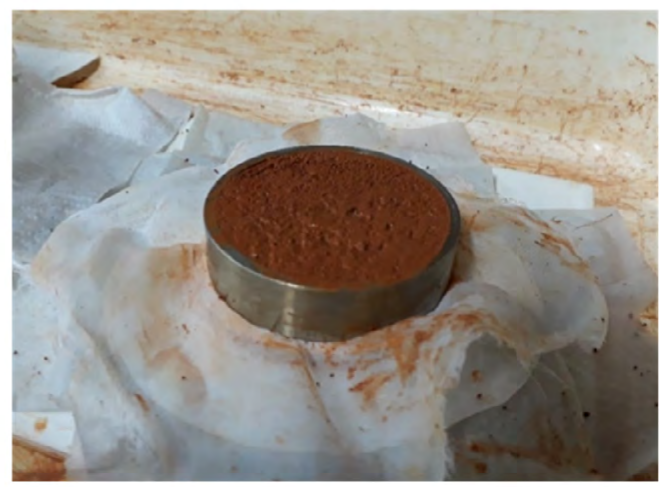

$\mathrm{D}$

Figura 5 Preparação dos corpos de prova da Amostra 2 para os ensaios edométricos. A. Esquema em corte do equipamento de reconstituição; B. Amostra na consistência de lama depositada no anel metálico; C. Compressão edométrica das amostras; D. Corpo de prova reconstituído. 
Quadro 1 Critérios de classificação da colapsibilidade nas obras de engenharia (Jennings \& Knight, 1975; Lutenegger \& Saber, 1988).

\begin{tabular}{|c|c|c|c|}
\hline \multicolumn{2}{|c|}{ Jennings \& Knight (1975) } & \multicolumn{2}{|c|}{ Lutenegger \& Saber (1988) } \\
\hline $\mathrm{PC}(\%)$ & Gravidade do problema & $\mathrm{PC}(\%)$ & Gravidade do probleme \\
\hline 0 a 1 & Sem problema & & \\
\hline 1 a 5 & Problema moderado & 2 & Leve \\
\hline 5 a 10 & Problemático & 6 & Moderada \\
\hline 10 a 20 & Problema grave & & \\
\hline$>20$ & Problema muito grave & 10 & Alta \\
\hline
\end{tabular}

limites de consistência ou nas condições de compacidade do solo (Vilar \& Ferreira, 2015).

A determinação das curvas características de retenção de água (relação entre o teor de umidade gravimétrico e a suç̧ão matricial) dos corpos de prova das Amostras 1 e 2 foi realizada utilizando-se a técnica da mesa de tensão, para sucções de 1,2 e $5 \mathrm{kPa}$, e a técnica da câmara de pressão, para suç̧ões de 10, 20, 50, 100, 200, 500 e $1500 \mathrm{kPa}$. As curvas de retenção foram obtidas por trajetórias de secagem, a partir de corpos de prova saturados por imersão em água destilada, após aplicação de vácuo durante um período de 24 horas. Para o ajuste das curvas, foi utilizado o modelo de van Genuchten (1980).

\section{Resultados e Discussões}

Na Tabela 1, são apresentados os resultados dos ensaios geotécnicos para a caracterização física do solo utilizado, na qual se observa tratar-se de uma argila arenosiltosa de elevada plasticidade.Na Figura 6, é apresentada a curva de compactação do solo na energia do ensaio Proctor Normal, a partir da qual verifica-se que, no ponto de ótimo, tem-se um teor de umidade ótimo $\left(\mathrm{w}_{\mathrm{ot}}\right)$ de $31,5 \%$ e um peso específico seco máximo $\left(\gamma_{\text {dmax }}\right)$ de $13,72 \mathrm{kN} / \mathrm{m}^{3}$. Com base no valor de $\mathrm{w}_{\mathrm{ot}}$, foi definido o teor de umidade da Amostra 1 , que foi de $29,5 \%\left(\mathrm{w}_{\mathrm{ot}}-2 \%\right)$.

Após a preparação da Amostra 1, por reconstituição hidrostática, foi obtido, para a mesma, um valor de peso específico seco $\left(\gamma_{\mathrm{d}}\right)$ igual a $10,5 \mathrm{kN} / \mathrm{m}^{3}$, o qual serviu de referência para definir os parâmetros de reconstituição da Amostra 2, na condição saturada. Assim, a partir do ponto cujas coordenadas se referem aos parâmetros da Amostra 1 , foi determinado o teor de umidade para a preparação da Amostra 2 (57,6\%), conforme mostrado na Figura 6. Com isso, foram obtidas duas amostras com o mesmo valor de $\gamma_{\mathrm{d}}$, as quais, apesar de apresentarem diferentes teores de umidade de reconstituição, resultaram em estruturas que correspondem a um único e elevado índice de vazios (e), cujo valor foi de 1,610 .
Na Figura 7, são apresentadas as curvas características de retenção de água obtidas para as Amostras 1 e 2 . As diferenças nas curvas de retenção, expressas pelas discordâncias nos valores de entrada de ar (s) e nas relações entre sucção e teor de umidade, indicam as diferentes estruturas resultantes das amostras reconstituídas, ainda que apresentem o mesmo valor de índice de vazios.

A Amostra 1, reconstituída com teor de umidade inferior ao de saturação, por apresentar menor valor de entrada de ar e uma maior inclinação da parte inicial da curva de retenção, em comparação com a Amostra 2 (reconstituída no teor de umidade de saturação), oferece menor resistência à dessaturação, ou seja, apresenta uma menor capacidade de retenção de água para o intervalo de sucção analisado. As diferenças observadas explicam-se pelas dimensões dos poros que estão diretamente relacionadas com as dimensões das agregações das partículas das amostras analisadas.

Os resultados indicam que o aumento do teor de umidade de moldagem das amostras, resultante do processo de reconstituição edométrica em relação ao teor de umidade de reconstituição hidrostática, promoveu uma reestruturação do material, resultando em uma estrutura mais homogênea, ou seja, na qual prevalece um maior grau de dispersão, com as partículas do solo mais orientadas. Como decorrência direta da reconstituição no teor de umidade de saturação, têm-se a diminuição dos poros da Amostra 2 e o consequente aumento da sucção, quando comparada à Amostra 1 (Vanapalli et al., 1999; Romero et al., 2011; Han \& Vanapalli, 2016a).

Os baixos valores de entrada de ar obtidos para as Amostras 1 e $2(1,4 \mathrm{kPa}$ e 3,9 $\mathrm{kPa}$, respectivamente) não correspondem aos valores típicos de solos de textura argilosa. Os resultados apresentados pelas amostras analisadas sugerem a formação de agregações das partículas (grumos de argilominerais) que, em função da sucção em seu interior, podem se comportar como grãos de areia (Sivakumar \& Wheeler, 2000; Benatti et al., 2013). Portanto, para baixos valores de sucção, as amostras comportam-se como solos de textura arenosa, e a macroestrutura, marcada 
Tabela 1 Caracterização física do solo utilizado. LL. Limite de liquidez; LP. Limite de Plasticidade; IP. Índice de Plasticidade.

\begin{tabular}{|c|c|c|c|c|c|c|c|c|}
\hline \multicolumn{3}{|c|}{ Limites de consistência (\%) } & \multicolumn{5}{|c|}{ Análise granulométrica (\%) } & \multirow{3}{*}{$\begin{array}{l}\text { Peso específico dos } \\
\text { sólidos, } \mathrm{Y}_{\mathrm{s}}\left(\mathrm{kN} / \mathrm{m}^{3}\right)\end{array}$} \\
\hline \multirow{2}{*}{ LL } & \multirow{2}{*}{ LP } & \multirow{2}{*}{$\mathbb{P}^{*}$} & \multicolumn{3}{|c|}{ Areia } & \multirow{2}{*}{ Silte } & \multirow{2}{*}{ Argila } & \\
\hline & & & Grossa & Média & Fina & & & \\
\hline 82 & 44 & 38 & 0 & 5 & 13 & 11 & 71 & 27,4 \\
\hline
\end{tabular}

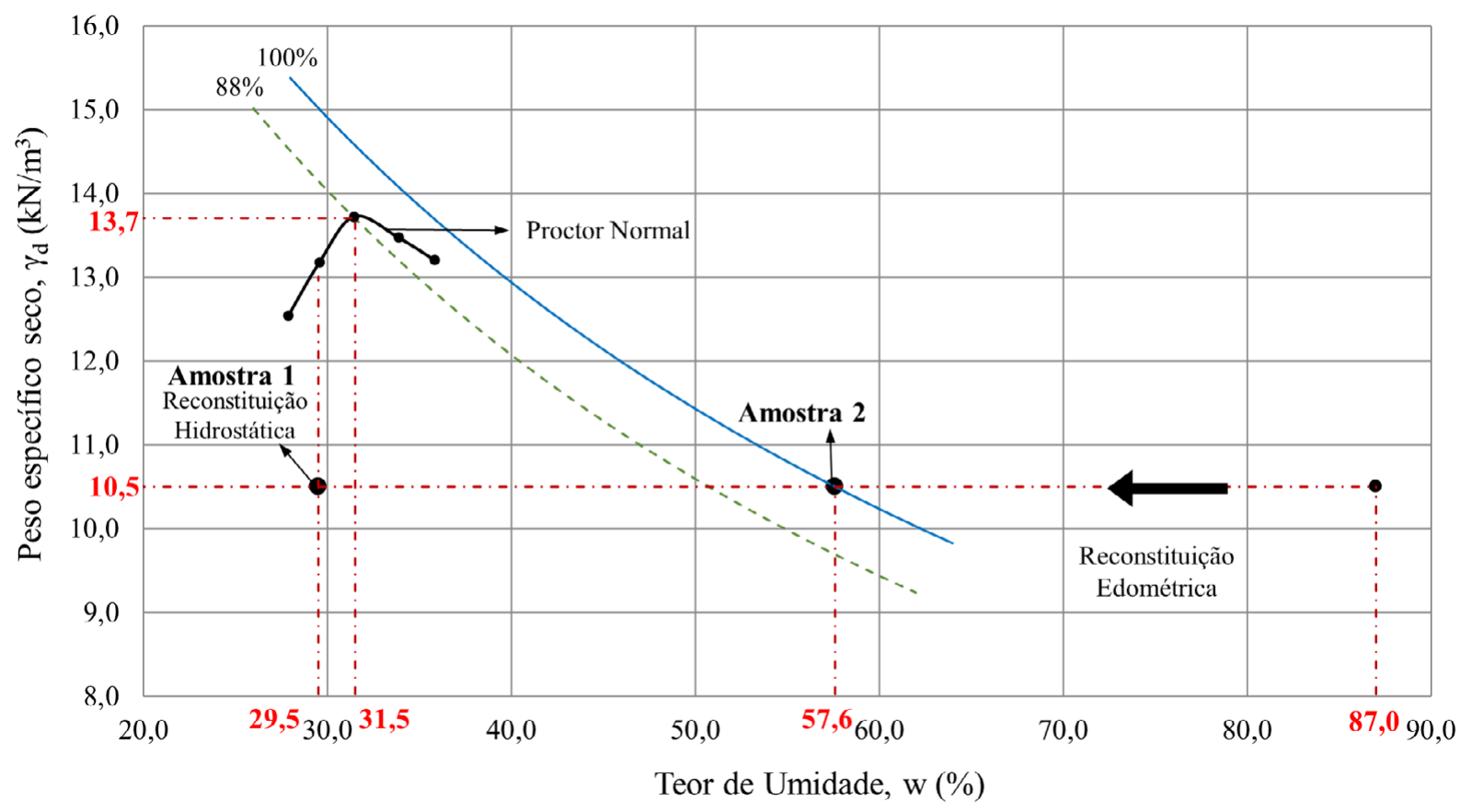

Figura 6 Curva de compactação do solo pesquisado na energia do ensaio Proctor Normal e curva de saturação para determinação dos parâmetros de reconstituição hidrostática e edométrica das Amostras 1 e 2.

por macroporos localizados entre as agregações, governa a dessaturação inicial.

Entretanto, a despeito das diferenças entre os processos de reconstituição adotados, a influência da umidade de compactação é de grande relevância, pois, para amostras reconstituídas com baixos teores de umidade de moldagem, como no caso da Amostra 1, os grumos resultantes são duros e difíceis de destruir. Segundo Tarantino (2011), em geral, tanto a compactação estática quanto a compactação dinâmica não são capazes de quebrar essas agregações das partículas. Dessa maneira, pode-se afirmar que a estrutura da Amostra 1 é constituída por maiores agregações de partículas e, consequentemente, maiores dimensões de macroporos. Em contrapartida, com o aumento do teor de umidade de moldagem, referente à Amostra 2, os grumos formados são mais suaves e deformáveis e o processo de compactação resulta em um maior grau de orientação das partículas e, por consequência, em vazios menores entre as agregações (Zhang et al., 2018;
Zou et al., 2018). Como se sabe, os valores de entrada de ar estão relacionados às dimensões dos poros que, por sua vez, refletem as dimensões das agregações das partículas. Sendo assim, de acordo com a Figura 7, a Amostra 1, por apresentar macroporos maiores, exibe um valor de entrada de ar inferior ao da Amostra 2.

Segundo Alonso et al. (2013), a estrutura de amostras compactadas com baixos teores de umidade de moldagem é caracterizada por uma maior distribuição de macroporos, e a água localizada em seus interiores é identificada como de natureza capilar, portanto, diferente da água que preenche os microvazios. Dessa maneira, baseando-se nas distribuições de macro e microporos das Amostras $1 \mathrm{e} 2$, respaldadas pelas diferenças entre seus valores de entrada de ar (Figura 7), presume-se que, para a Amostra 1, os fenômenos de capilaridade são mais importantes na determinação do seu comportamento hidromecânico, ao passo que para a Amostra 2, moldada na condição saturada, a parcela osmótica pode ter relevância, em particular quando estão 


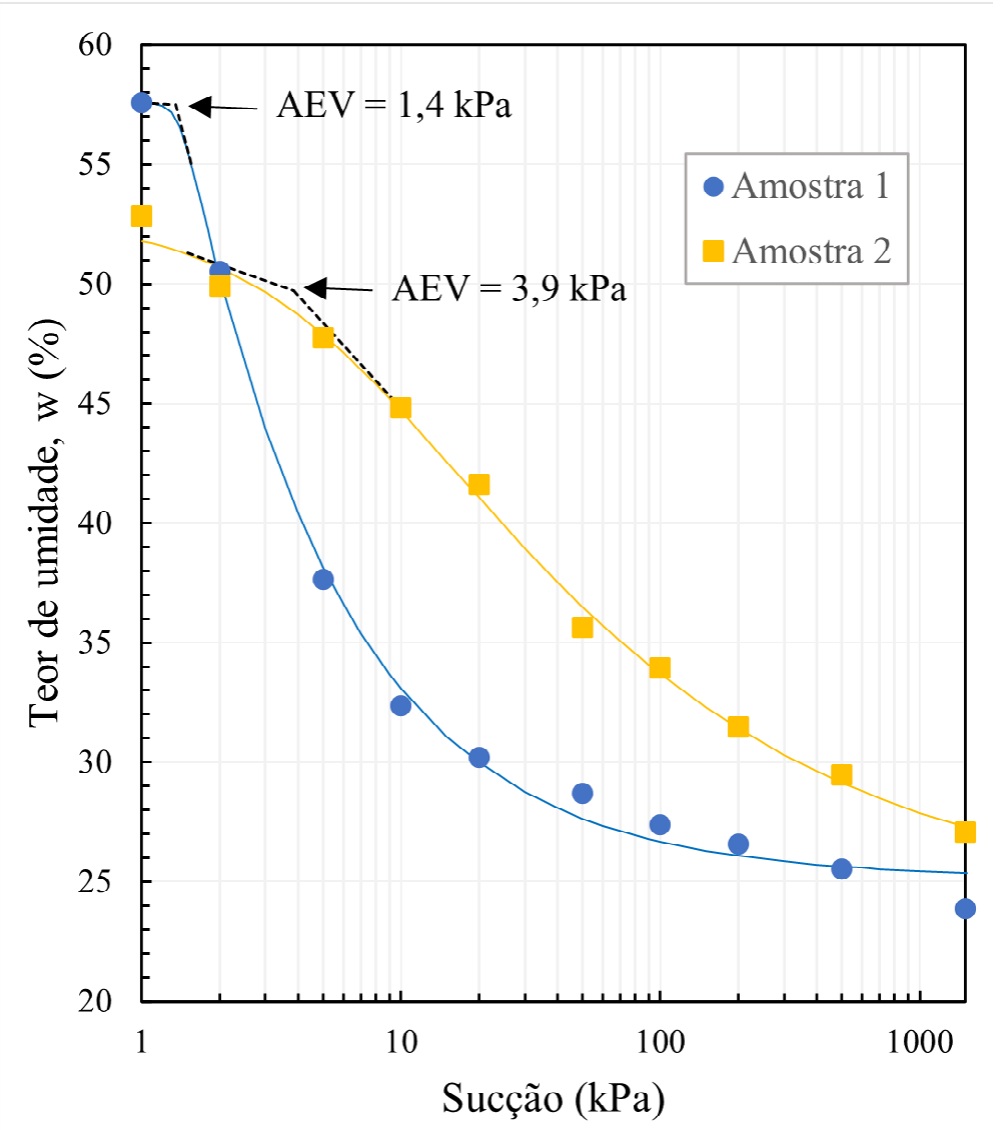

Figura 7 Curvas características de retenção de água das Amostras 1 e 2.

em jogo as interações de natureza eletroquímica entre a água, os íons nela presentes e os argilominerais (Alonso et al., 2013; Maranha das Neves, 2016).

Na Figura 8, são apresentadas as curvas que relacionam a variação do índice de vazios (e) com a tensão vertical $\left(\sigma_{v}\right)$, referentes aos ensaios edométricos realizados com os corpos de prova das Amostras 1 e 2.

As diferenças apresentadas pelas curvas de compressão dos corpos de prova das Amostras 1 e 2 estão relacionadas com as diferentes estruturas obtidas pelos dois procedimentos de reconstituição adotados, ou seja, refletem a diferença estrutural dos corpos de prova em função do teor de umidade de moldagem. A curva de compressão do corpo de prova CP1 (Amostra 1), ensaiado sem inundação, é caracterizada por um trecho inicial de comportamento aproximadamente elástico e um trecho virgem bem definido, que marca a mudança para um comportamento elastoplástico. Presume-se que, no trecho inicial dessa curva de compressão, os grumos de argilominerais sejam ligeiramente comprimidos sem que grandes movimentos relativos entre suas partículas aconteçam e, portanto, sem que a estrutura floculada do material seja consideravelmente alterada.
Esse comportamento, apresentado pelo corpo de prova $\mathrm{CP} 1$ e também pelos CP3 e CP4, antes de serem inundados, pode ser explicado pela presença da sucção, responsável por manter uma estrutura porosa de natureza metaestável e promover o enrijecimento do material durante o carregamento (Benatti et al., 2013). A redução da sucção pela inundação dos corpos de prova $\mathrm{CP} 2, \mathrm{CP} 3$ e CP4 resulta na quebra e reorganização das agregações, com apreciável deslocamento entre as partículas, ocasionando o colapso da estrutura inicial, que se reflete, nas curvas de compressão, por uma brusca redução do índice de vazios (Bakir et al., 2017).

As curvas de compressão dos corpos de prova CP2 (inundado no início do ensaio) e CP5 (ensaiado no teor de umidade de moldagem de saturação), são caracterizadas por trechos virgens bem definidos e que compreendem todo o intervalo de tensões analisado. Esses resultados corroboram com os obtidos por Sun et al. (2007) em corpos de prova compactados. Além disso, como se observa na Figura 8, as curvas de compressão dos corpos de prova da Amostra 1 (CP2, CP3 e CP4), após inundação, tenderam a se sobrepor e se tornaram paralelas à do corpo de prova da Amostra 2 (CP5). 


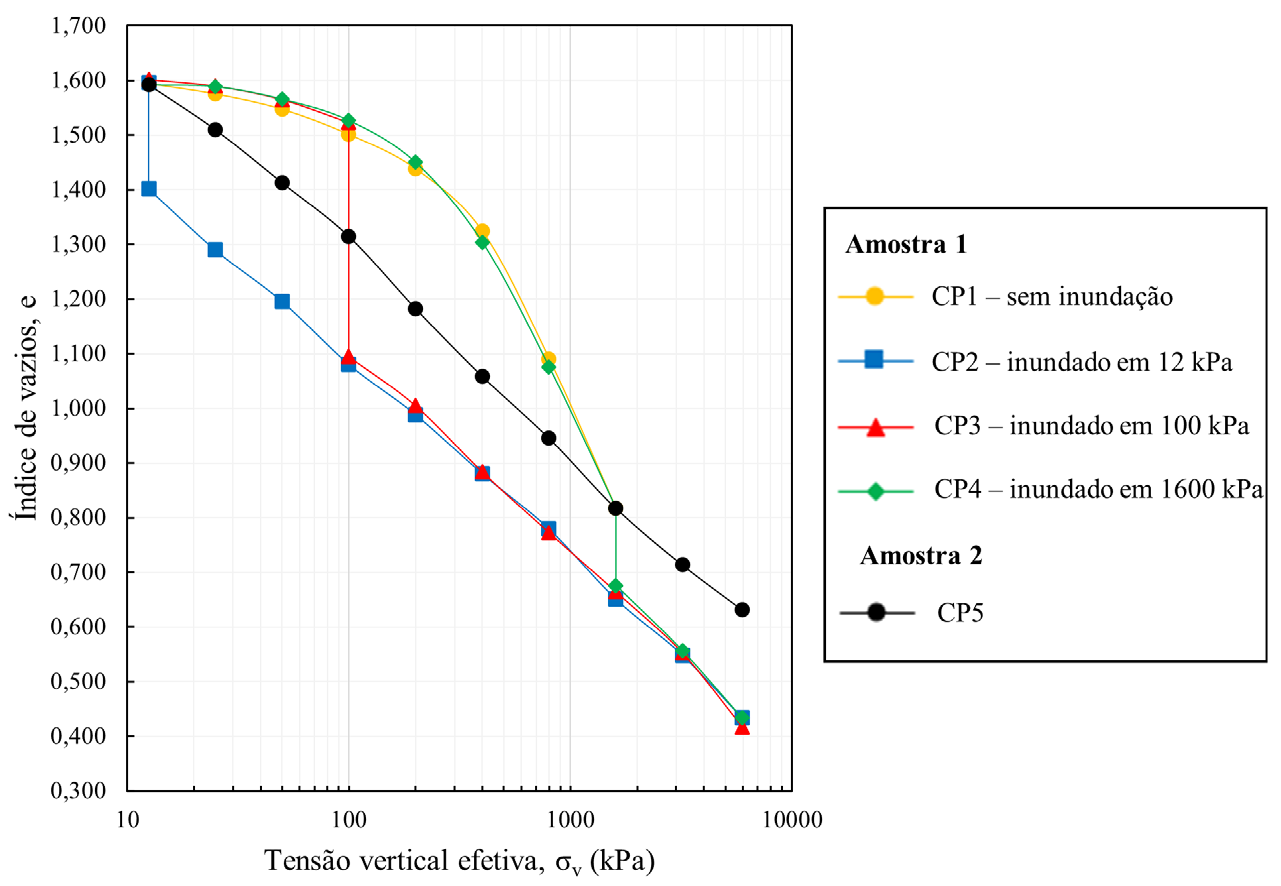

Figura 8 Curvas e versus log $\sigma_{v}$ resultantes dos ensaios edométricos.

Esse comportamento pode ser explicado pela redução do efeito da sucção atuante nos corpos de prova da Amostra 1 devido ao aumento do grau de saturação. A inundação desses corpos de prova acarretou o colapso de suas estruturas iniciais, com consequente redução das agregações de argila e dos poros entre essas agregações, tendendo a uma maior orientação das partículas do solo, cuja estrutura se assemelha à do corpo de prova CP5, referente à Amostra 2. Ademais, o deslocamento relativo entre as curvas das Amostras 1 e 2 é o reflexo da diferença das estruturas dos corpos de prova no início do ensaio, decorrentes dos diferentes teores de umidade de moldagem adotados.

Observam-se, ainda nas curvas de compressão da Amostra 1, que os estados finais posteriores ao término das deformações por colapso dos corpos de prova $\mathrm{CP} 2$, CP3 e CP4, induzidas pelo aumento do grau de saturação (inundação), independem do nível de tensão vertical em que ocorre a inundação. Tal comportamento é ilustrado pela sobreposição das curvas de compressão dos corpos de prova CP3 e CP4, após inundação, com a curva do corpo de prova CP2, inundado desde o início do ensaio.

Portanto, as discussões apresentadas nos dois parágrafos anteriores permitem concluir que, nas deformações por colapso, o efeito do nível de tensão vertical em que ocorre a inundação do solo tem menor influência no resultado final, quando comparado à influência das variações da estrutura dos corpos de prova. Conclusões similares foram encontradas por Jiang et al. (2012) através de diversas trajetórias de tensões em corpos de provas compactados de um solo colapsível, utilizando-se de ensaios edométricos e ensaios triaxiais com controle de deformações e de tensões.

Além disso, a tendência de convergência do trecho virgem da curva de compressão do corpo de prova CP1, não inundado, em relação à curva do corpo de prova CP2, inundado desde o início do ensaio, indica que as magnitudes das deformações por colapso variam da seguinte forma: crescem inicialmente com o aumento da tensão vertical, atingem um valor máximo e, por fim, se reduzem, aproximando-se do valor nulo, para tensões verticais elevadas.

Com base nessa observação e na não dependência da sequência de carregamento/umedecimento, o potencial de colapso (PC) do corpo de prova CP1 (Amostra 1) em cada nível de tensão vertical foi estimado a partir das curvas de compressão dos corpos de prova CP1 e CP2, cuja representação gráfica é apresentada na Figura 9.

A análise da Figura 9, tomando como base o critério de Jennings \& Knight (1975), permite verificar que o potencial de colapso (PC), para uma condição do solo no campo semelhante à do CP1, será de $18,4 \%$ na tensão vertical de $200 \mathrm{kPa}$, condição esta que se enquadra na faixa de "problema grave". Para uma tensão de $300 \mathrm{kPa}$, conforme considerado no critério de Lutenegger \& Saber (1988), o valor do PC seria de aproximadamente $19,1 \%$, o 


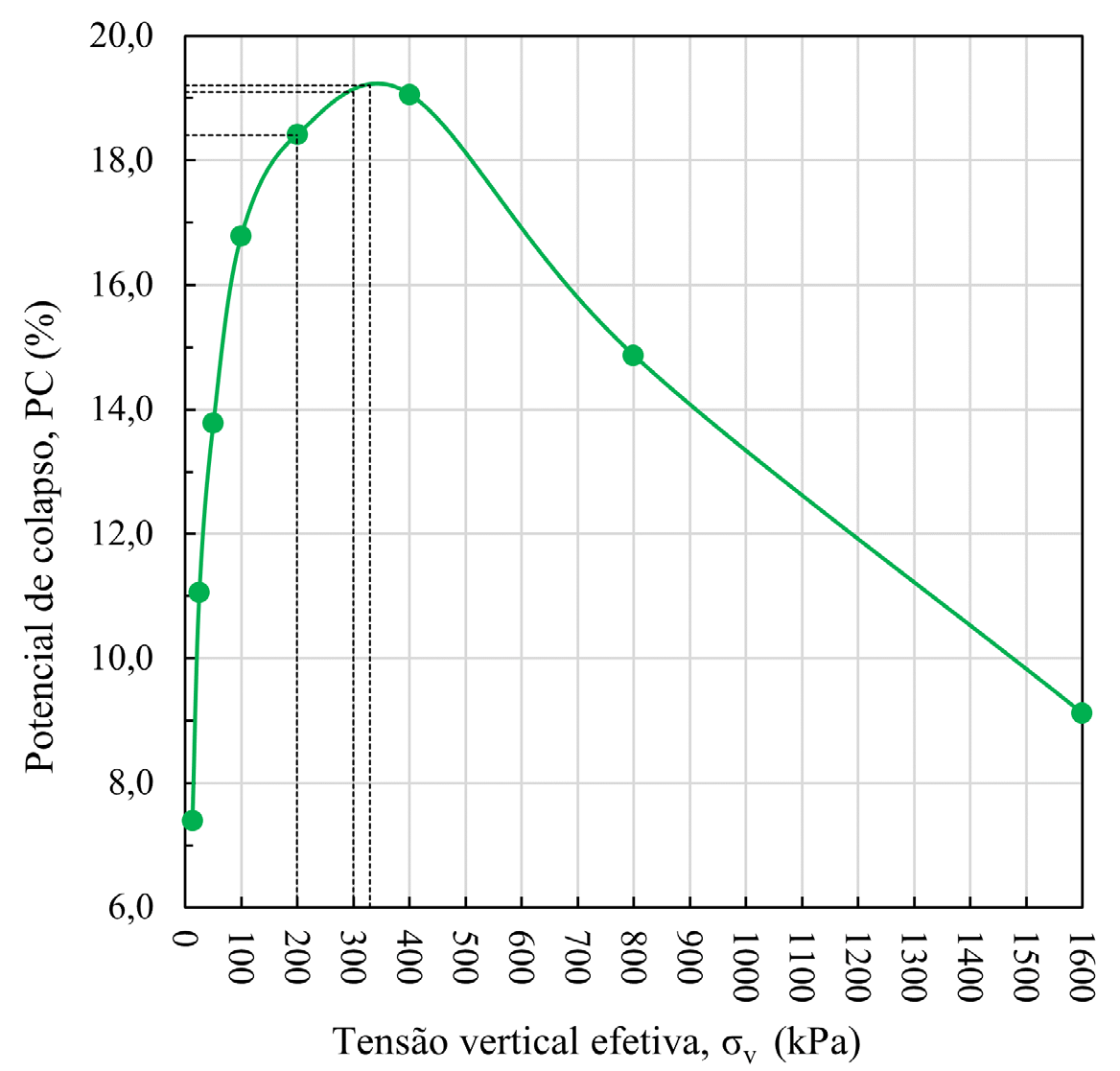

Figura 9 Valores de potencial de colapso (PC) do corpo de prova CP1 (Amostra 1) em função da tensão vertical $\left(\sigma_{v}\right)$.

que resulta no enquadramento do material na categoria de alta susceptibilidade ao colapso ("gravidade do problema alto"). Em relação ao critério de Vargas (1978), o solo nas condições do CP1 será considerado colapsível para todos os valores de tensões utilizados nos ensaios, pois o PC é sempre superior a $2 \%$.

O PC máximo do CP1 (Amostra 1), de acordo com a Figura 9, foi de 19,2\% para a tensão de $330 \mathrm{kPa}$, valor bem próximo do obtido pela proposta de Jennings \& Knight (1988). Já o critério de Vargas (1978), por considerar uma tensão de referência qualquer, é bastante coerente, uma vez que os solos colapsíveis podem apresentar valor de PC superior a $2 \%$ para tensões verticais que divergem dos valores de 200 ou $300 \mathrm{kPa}$, inclusive para baixos níveis de tensões, como é o caso do solo na condição do CP1. Todavia, o critério de Jennings \& Knight (1975) é o único dentre os apresentados que busca classificar o solo colapsível por intervalos de valores de potencial de colapso. Assim sendo, nada mais razoável que este critério seja aplicável para qualquer nível de tensões, e não apenas para a tensão de referência de $200 \mathrm{kPa}$.

Portanto, todos os critérios apontam uma elevada susceptibilidade ao colapso para o solo na condição da
Amostra 1, quando o carregamento é realizado com o solo no teor de umidade de moldagem. Esta susceptibilidade ao colapso se aplica a uma extensa faixa de tensões verticais, incluindo valores muito prováveis de ocorrer em obras de engenharia, inclusive inferiores a $100 \mathrm{kPa}$.

\section{Conclusão}

As diferenças nas curvas características de retenção de água e nas curvas de compressão dos ensaios edométricos mostraram que as estruturas obtidas nas Amostras 1 e 2, em função das condições em que foram reconstituídas, influenciaram de modo marcante o comportamento do solo.

Em relação às curvas características de retenção de água, a Amostra 1 (reconstituída hidrostaticamente com teor de umidade inferior ao de saturação) ofereceu menor resistência à dessaturação em comparação com a Amostra 2 (reconstituída edometricamente no teor de umidade de saturação) para o intervalo de sucção analisado. $\mathrm{O}$ aumento do teor de umidade de reconstituição das amostras, resultante do processo de reconstituição edométrica em relação ao teor de umidade de reconstituição hidrostática, é responsável por uma reestruturação do material, resultando em um 
grau de dispersão das partículas do solo constituintes da Amostra 2. Como decorrência, têm-se a diminuição de seus poros e um consequente aumento da sucção, quando comparada à Amostra 1.

Além disso, os baixos valores de entrada de ar obtidos para as Amostras 1 e 2 sugerem a formação de agregações das partículas de argila, comportando-se como solos de textura arenosa. Portanto, para baixos valores de suç̧ão, a macroestrutura governa a dessaturação inicial das amostras. É importante salientar que, para além das curvas características de retenção de água, as técnicas de microscopia eletrônica de varredura e de porosimetria por intrusão de mercúrio também fornecem, respectivamente, estimativas qualitativas e quantitativas das agregações e dos poros na estrutura dos solos reconstituídos.

A influência da umidade de reconstituição das amostras foi de grande relevância no comportamento do solo. Os grumos presentes na preparação da Amostra 1 são difíceis de destruir, resultando em uma maior distribuição de macroporos, ao passo que o processo de reconstituição da Amostra 2 resultou em vazios menores entre as agregações. O menor valor de entrada de ar obtido para a Amostra 1, em relação à Amostra 2, reflete a diferença entre as dimensões dos poros das amostras analisadas e permite inferir que, para a Amostra 1, os fenômenos de capilaridade são mais importantes na determinação do seu comportamento hidromecânico, enquanto que para a Amostra 2, na condição saturada, as forças de adsorção são relevantes com relação à resposta do material frente às solicitações.

Essas observações também justificam o comportamento apresentado pelos corpos de prova das Amostras 1 e 2, quanto às curvas de compressão dos ensaios edométricos. A sucção capilar é responsável por manter a estrutura porosa de natureza metaestável e promover o enrijecimento dos corpos de prova da Amostra 1 durante o carregamento. Com base nesse comportamento, acreditase que a redução da sucção pelo aumento do grau de saturação (inundação) possa ser apontada como a causa principal do colapso da estrutura inicial dos corpos de prova dessa amostra. Além disso, observou-se que as curvas de compressão dos corpos de prova da Amostra 1, após inundação, tenderam a se sobrepor e se tornarem paralelas à do corpo de prova da Amostra 2, reconstituída na condição saturada. O deslocamento relativo entre as curvas dessas amostras é o reflexo da diferença das estruturas dos corpos de prova no início do ensaio, decorrentes dos diferentes teores de umidade de moldagem adotados.

Observou-se que, nas deformações por colapso, o efeito do nível de tensão em que ocorre a inundação do solo tem menor influência no resultado final, do que as variações da estrutura dos corpos de prova.

Todos os critérios de avaliação do potencial de colapso (PC) utilizados (Jennings \& Knight, 1975;
Lutenegger \& Saber 1988; Vargas, 1978) apontaram uma elevada susceptibilidade ao colapso para o solo reconstituído com baixo teor de umidade e elevado índice de vazios, para uma extensa faixa de tensões verticais, que incluem valores muito prováveis de ocorrer em obras de engenharia, inclusive inferiores a $100 \mathrm{kPa}$.

Destaca-se que o aumento do teor de umidade de moldagem dos corpos de prova promoveu uma alteração radical no comportamento subsequente do material. Não somente o estado inicial do solo foi afetado (sucção inicial após a reconstituição), mas as posições dos trechos virgens de compressão para diferentes valores de sucção inicial, fortemente influenciadas pelo teor de umidade de reconstituição. Isso sugere que as diferentes das estruturas promovidas pela alteração do teor de umidade de moldagem,

Destaca-se que o aumento do teor de umidade de moldagem dos corpos de prova promoveu uma inequívoca alteração no comportamento subsequente do material. Não somente o estado inicial do solo foi afetado (sucção inicial após a reconstituição), mas as posições dos trechos virgens de compressão para diferentes valores de sucção inicial. Isso sugere que as diferenças estruturais promovidas pela alteração do teor de umidade de moldagem dos corpos de prova são suficientemente significativas para que os materiais sejam tratados como fundamentalmente diferentes. Dentro do contexto da modelagem constitutiva desses materiais, isso significa que não seria possível modelar o comportamento de solos reconstituídos sob uma ampla gama de teores de umidade utilizando um único conjunto de parâmetros elastoplásticos.

\section{Agradecimentos}

Os autores agradecem à Capes pelo apoio financeiro concedido à pesquisa.

\section{Referencias}

ABNT. 1990. Associação Brasileira de Normas Técnicas. NBR 12007: Solo - Ensaio de adensamento unidimensional Método de ensaio. Rio de Janeiro, 15 p.

ABNT. 2016a. Associação Brasileira de Normas Técnicas. NBR 7181: Solo - Análise granulométrica. Rio de Janeiro, 12 p.

ABNT. 2016b. Associação Brasileira de Normas Técnicas. NBR 6459: Solo - Determinação do Limite de Liquidez. Rio de Janeiro, 5 p.

ABNT. 2016c. Associação Brasileira de Normas Técnicas. NBR 7180: Solo- Determinação do Limite de Plasticidade. Rio de Janeiro, 3 p.

ABNT. 2016d. Associação Brasileira de Normas Técnicas. NBR 6458: Grãos de pedregulho retidos na peneira de abertura 4,8 $\mathrm{mm}$ - Determinação da massa específica, da massa específica aparente e da absorção de água. Rio de Janeiro, 10 p.

ABNT. 2016e. Associação Brasileira de Normas Técnicas. NBR 7182: Solo - Ensaio de compactação. Rio de Janeiro, 9 p. 
Ajdari, M.; Habibagahi, G. \& Masrouri, F. 2013. The role of suction and degree of saturation on the hydro-mechanical response of a dual porosity silt-bentonite mixture. Applied Clay Science, 83-84: 83-90.

Alonso, E.E.; Pinyol, N.M. \& Gens, A. 2013. Compacted soil behavior: initial state, structure and constitutive modelling. Géotechnique, 63(6): 463-478.

Bakir, N.; Abbeche, K. \& Panczer, G. 2017. Experimental study of the effect of the glass fibers on reducing collapse of a collapsible soil. Geomechanics and Engineering, 12(1): 71-83.

Benatti, J.C.B., Rodrigues, R.A. \& Miguel, M.G. 2013. Aspects of Mechanical Behavior and Modeling of a Tropical Unsaturated Soil. Geotechnical and Geological Engineering, 31:15691585.

Cordão Neto, M.P.; Hernández, O.; Reinaldo, R.L.; Borges, C. \& Caicedo, B. 2018. Study of the relationship between the hydromechanical soil behaviour and microstructure of a structured soil. Earth Sciences Research Journal, 22(2): 91101.

Crispim, F.A.; Lima, D.C.; Schaefer, C.E.G.R.; Silva, C.H.C.; Carvalho, C.A.B.; Barbosa, P.S.A. \& Brandão, E.H. 2011. The influence of laboratory compaction methods on structure: mechanical and micromorphological analyses. Soils and Rocks, 34(1): 91-98.

Cui, Y.J.; Nguyen, X.P.; Tang, A.M. \& Li, X.L. 2013. An insight into the unloading/reloading loops on the compression curve of natural stiff clays. Applied Clay Science, 83-84: 343-348.

Della Vecchia, G.; Dieudonné; A.C.; Jommi; C. \& Charlier; R. 2015. Accounting for evolving pore size distribution in water retention models for compacted clays. International Journal for Numerical and Analytical Methods in Geomechanics, 39: 702-723.

Habasimbi, P. \& Nishimura, T. 2019. Soil water characteristic curve of an unsaturated soil under low matric suction ranges and different stress conditions. International Journal of Geosciences, 10: 39-56.

Han, Z. \& Vanapalli, S. K. 2016a. Relationship between resilient modulus and suction for compacted subgrade soils. Engineering Geology, 211: 85-97.

Han, Z. \& Vanapalli, S. K. 2016b. Stiffness and shear strength of unsaturated soils in relation to soil-water characteristic curve. Géotechnique, 66(8):627-647.

Islam, T. \& Kodikara, J. 2016. Interpretation of loading/wetting behaviour of compacted soils within the MKP framework: Part I Static compaction. Canadian Geotechnical Journal, 53(5): 783-805.

Jennings, J.E. \& Knight, K. 1975. A Guide to Construction on or with Materials Exhibiting Additional Settlement due to a Collapse of Grain Structure. In: REGIONAL CONFERENCE FOR AFRICA ON SOIL MECHANICS AND FOUNDATION ENGINEERING, 6, Durban, 1975. Proceedings, Durban, p. 99-105.

Jiang, M.J.; Hu, H.J. \& Liu, F. 2012. Summary of collapsible behavior of artificially structural loess in oedometer and triaxial wetting tests. Canadian Geotechnical Journal, 49(10):1147-1157.
Kodikara, J.; Islam, T. \& Rejeev, P. 2016. Interpretation of loading/wetting behaviour of compacted soils within the MKP framework: Part II Dynamic compaction. Canadian Geotechnical Journal, 53(5): 806-827.

Li, P.; Vanapalli, S.K. \& Li, T. 2016. Review of collapse triggering mechanism of collapsible soils due to wetting. Journal of Rock Mechanics and Geotechnical Engineering, 8: 256-274.

Lutenegger, A.J. \& Saber, R.T. 1988. Determination of Collapse Potential of Soils. Geotechnical Testing Journal, 11(3): 173178.

Maranha das Neves, E. 2016. Mecânica dos Estados Críticos: solos saturados e não saturados. 1. ed., Lisboa, IST Press, 528 p.

Mascarenha, M.M.A.; Cordão Neto, M.P. \& Silva, M.T.M.G. 2016. Alternative method for analysing hydromechanical behaviour of unsaturated soils. Soils and Rocks, 39(1): 29-39.

Ng, C.W.W.; Sedeghi, H.; Hossen, S.K.B.; Chiu, C.F.; Alonso, E.E. \& Baghbanrezvan, S. 2016. Water retention and volumetric characteristics of intact and re-compacted loess. Canadian Geotechnical Journal, 53(8): 1258-1269.

Otalvaro, I.F.; Cordão Neto, M.P.; Delage, P. \& Caicedo, B. 2015. Compressibility and microstructure of compacted laterites. Transportation Geotechnics, 5: 20-34.

Otalvaro, I.F.; Cordão Neto, M.P.; Delage, P. \& Caicedo, B. 2016. Relationship between soil structure and water retention properties in a residual compacted soil. Engineering Geology, 205: 73-80.

Resende, M.; Curi, N.; Rezende, S.B. \& Corrêa, G.F. 2007. Pedologia: Base para distinção de ambientes. 5.ed., Viçosa, UFLA, $322 \mathrm{p}$.

Romero, E.; Della Vecchia, G. \& Jommi, C. 2011. An insight into the water retention properties of compacted clayey soils. Géotechnique, 61(4): 313-328.

Sivakumar, V. \& Wheeler, S.J. 2000. Influence of compaction procedure on the mechanical behaviour of an unsaturated compacted clay. Géotechnique, 50(4): 359-368.

Sun, D.; Sheng, D. \& Xu, Y. 2007. Collapse behaviour of unsaturated compacted soils with different initial densities. Canadian Geotechnical Journal, 44(6): 673-686.

Tarantino, A. 2011. Compacted versus reconstituted states. In: ALONSO, E.E. \& GENS, A. (eds.). Unsaturated Soils: Proceedings of the Fifth International Conference on Unsaturated Soils, 2010, Barcelona, Spain. London, CRC Press, p. 113-136.

Tatsuoka, F. \& Correia, A.G. 2018. Importance of controlling the degree of saturation in soil compaction linked to soil structure design. Transportation Geotechnics, 17: 3-23.

Teixeira, W.G. \& Bhering, S.B. 2017. Retenção de água no solo pelos métodos da mesa de tensão e da câmara de Richards. In: TEIXEIRA, P.C.; DONAGEMMA, G.K.; FONTANA, A. \& TEIXEIRA, W.G. (eds.). Manual de métodos de análise de solo. 3. ed. rev. e ampl., cap. 4, Brasília, Embrapa, p. 34-46.

Vanapalli, S.K.; Fredlund, D.G. \& Pufahl, D.E. 1999. The influence of soil structure and stress history on the soil-water characteristics of a compacted till. Géotechnique, 49(2): 143-159. 
van Genuchten, M.T. 1980. A closed-form equation for predicting the hydraulic conductivity of unsaturated soils. Soil Science Society of America Journal, 44: 892-898.

Vargas, M. 1978. Introdução à Mecânica dos Solos. 2. ed., São Paulo, McGraw Hill do Brasil, 509 p.

Vilar, O.M. \& Ferreira, S.R.M. 2015. Solos colapsíveis e expansivos. In: CARVALHO, J.C.; GITIRANA JUNIOR, G.F.N.; MACHADO, S.L.; MASCARENHA, M.M.A. \& SILVA FILHO, F.C (orgs.). Solos não saturados no contexto geotécnico. São Paulo: ABMS, p. 415-427.
Villar, O.M. \& Rodrigues, R.A. 2011. Collapse behavior of soil in a Brazilian region affected by a rising water table. Canadian Geotechnical Journal, 48(2): 226-233.

Zhang, T.W.; Cui, Y.J.; Lamas-Lopes, F.; Calon, N. \& D'aguir, S.C. 2018. Compacted soil behaviour through changes of density, suction and stiffness of soils with remoulding water content. Canadian Geotechnical Journal, 55(2): 182-190.

Zou, W.; Han, Z.; Vanapalli; S.K.; Zhang, J. \& Zhao, G. 2018. Predicting volumetric behavior of compacted clays during compression. Applied Clay Science, 155: 116-225.

\section{Como citar:}

Oliveira, N.M.; Dias Neto, S.L.S; Ferraz, R.L.; Pitanga, H.N.; Silva, T.O.; Barbosa, P.S.A. \& Lima, D.C. 2021. Influência da Estrutura na Curva Característica de Retenção e no Comportamento Colapsível de um Solo Tropical. Anuário do Instituto de Geociências, $44: 35335$. DOI 1982-3908_2021_44_35335 